\title{
Resposta do feijoeiro ao manejo de nitrogênio em várzeas tropicais ${ }^{(1)}$
}

\author{
Alberto Baêta dos Santos ${ }^{(2)}$, Nand Kumar Fageria ${ }^{(2)}$, Osmira Fátima da Silva(2) \\ e Meire Lúcia Barros de Melo ${ }^{(3)}$
}

\begin{abstract}
Resumo - O objetivo deste trabalho foi avaliar, por três anos consecutivos, os efeitos do manejo de $\mathrm{N}$ na produtividade e nas características agronômicas do feijoeiro cultivado em várzeas e a economicidade desta prática. Nos dois primeiros anos, utilizando a cultivar Rudá, foram avaliadas as doses de $0,40,80$, 120 e $160 \mathrm{~kg} \mathrm{ha}^{-1}$ de $\mathrm{N}$ e os métodos e épocas de aplicação de $\mathrm{N}$ : na semeadura, $1 / 2$ na semeadura + $1 / 2$ incorporado ao solo aos 20 dias após a emergência (DAE) e $1 / 2$ na semeadura $+1 / 2$ a lanço aos 20 DAE. No terceiro ano, avaliaram-se todas as doses de $\mathrm{N}$ incorporadas ao solo aos $20 \mathrm{DAE}$, com a cultivar Pérola. A maior produtividade econômica, $2.700 \mathrm{~kg} \mathrm{ha}^{-1}$ de grãos foi obtida com $167 \mathrm{~kg} \mathrm{ha}^{-1} \mathrm{de} \mathrm{N}$ incorporados ao solo aos 20 DAE na cultivar Pérola. A dose de $108 \mathrm{~kg} \mathrm{ha}^{-1} \mathrm{de} \mathrm{N}$ incorporada ao solo aos 20 DAE proporcionou a esta cultivar $90 \%$ da produtividade máxima. A aplicação de parte do $\mathrm{N}$ na semeadura e parte incorporada ao solo aos 20 DAE foi a mais eficaz. $\mathrm{O}$ feijoeiro requer mais $\mathrm{N}$ no cultivo de várzeas que nos sistemas tradicionais em terras altas.
\end{abstract}

Termos para indexação: Phaseolus vulgaris, componente de produção, adubo nitrogenado, adubação, característica agronômica.

\section{Performance of common bean affected by nitrogen management in tropical varzea soils}

\begin{abstract}
The objective of this work was to determine the effects of $\mathrm{N}$ management on yield and agronomic traits of common bean and the profitability of $\mathrm{N}$ application. The experiment was carried out for three years on varzea (lowland) soil. In the first two years, $\mathrm{N}$ doses used were $0,40,80,120$, and $160 \mathrm{~kg} \mathrm{ha}^{-1}$ and $\mathrm{N}$ applications were as follows: all $\mathrm{N}$ applied at sowing, $1 / 2$ at sowing $+1 / 2$ incorporated in the soil at 20 days after plant emergence and $1 / 2$ at sowing and $1 / 2$ applied as topdressing 20 days after plant emergence. In the third year, $\mathrm{N}$ doses applied at 20 days after plant emergence and incorporated in soil were evaluated in three localities. The bean cultivars used were Rudá in the first two years and Pérola in the last one. Maximum economical grain yield of $2.700 \mathrm{~kg} \mathrm{ha}^{-1}$ was obtained in Pérola cultivar with the application of $167 \mathrm{~kg} \mathrm{ha}^{-1}$ of $\mathrm{N}$ incorporated in the soil at 20 days after plant emergence; $\mathrm{N}$ dosage of $108 \mathrm{~kg} \mathrm{ha}^{-1}$ provided $90 \%$ of maximum grain yield. The most appropriate $\mathrm{N}$ application timing was part at sowing and part incorporated in the soil. Common bean crop requires more $\mathrm{N}$ in varzea soils than in upland soils.
\end{abstract}

Index terms: Phaseolus vulgaris, yield components, nitrogen fertilizers, fertilizer application, agronomic characters.

\section{Introdução}

O uso sustentável de várzeas compreende a utilização de sistemas de cultivos múltiplos, produzindo duas a três safras por ano numa mesma área. O cultivo do feijoeiro irrigado por subirrigação, na entressafra

\footnotetext{
(1) Aceito para publicação em 18 de setembro 2003.

${ }^{(2)}$ Embrapa-Centro Nacional de Pesquisa de Arroz e Feijão (CNPAF), Caixa Postal 179, CEP 75375-000 Santo Antônio de Goiás, GO. E-mail: baeta@cnpaf.embrapa.br fageria@cnpaf.embrapa.br, osmira@cnpaf.embrapa.br

(3) CNPAF. Bolsista do CNPq.
}

do arroz, tem-se mostrado uma alternativa viável em aumentar a produtividade de grãos no ecossistema várzea (Santos \& Silveira, 1996). O feijoeiro é uma planta exigente em nutrientes e, por ser de ciclo curto, necessita que eles estejam prontamente disponíveis nos momentos de demanda, para não limitar a produtividade (Silva \& Silveira, 2000).

A maioria das recomendações de adubação nitrogenada para o feijoeiro refere-se ao cultivo em terras altas, sem irrigação. Cardoso et al. (1978), Feitosa et al. (1980) e Almeida et al. (1982) obtiveram resposta linear do feijoeiro a esse fertilizante, ou seja, 
não se atingiu o máximo potencial produtivo desta cultura; as produtividades raramente ultrapassavam $1.500 \mathrm{~kg} \mathrm{ha}^{-1}$. Barbosa Filho \& Silva (1994), Silva \& Silveira (2000) e Stone \& Moreira (2001) verificaram efeito positivo da fertilização nitrogenada, em que esta leguminosa chegou a responder a doses acima de $100 \mathrm{~kg} \mathrm{ha}^{-1}$ de $\mathrm{N}$, especialmente em sistemas de cultivo associados a outras tecnologias, como a irrigação, que exigem mais $\mathrm{N}$, mas são mais produtivos. Os sistemas agrícolas influenciam as respostas do feijoeiro à adubação nitrogenada (Silva \& Silveira, 2000), portanto, o cultivo desta leguminosa em várzeas, necessita de ajustes em seu manejo.

O N é o nutriente absorvido em quantidades mais elevadas pelo feijoeiro (Oliveira et al., 1996). Aproximadamente $50 \%$ do $\mathrm{N}$ total absorvido é exportado para os grãos e o restante permanece no solo, na forma de resíduos culturais (Oliveira et al., 1996; Fageria et al., 1999). Com isso, entre as deficiências nutricionais que ocorrem na cultura do feijoeiro, a do N é a mais frequiente. A maximização do uso de $\mathrm{N}$ pelo feijoeiro é importante por causa dos aspectos econômicos e ambientais, pois este nutriente apresenta risco ao meio ambiente por ser potencialmente contaminante de lençóis freáticos. O conhecimento do manejo do $\mathrm{N}$ é fundamental em aumentar a eficiência de seu uso. Os sistemas agrícolas futuros devem ser economicamente viáveis, ecologicamente sustentáveis e social e politicamente aceitáveis (Fageria et al., 1999). Por ser o N um elemento que se perde facilmente por lixiviação, volatilização e desnitrificação no sistema solo-planta (Fageria et al., 1999), o manejo adequado da adubação nitrogenada é tido como um dos mais difíceis. Assim, torna-se necessário determinar a curva de resposta da cultura em relação a várias doses do nutriente, e adotar o método mais adequado de aplicação, pois este afeta o comportamento do N no solo e sua eficiência para as culturas (Fageria et al., 1999).

O objetivo deste estudo foi avaliar os efeitos de doses e de métodos e épocas de aplicação de $\mathrm{N}$ na produtividade e nas características agronômicas do feijoeiro cultivado em várzeas e a economicidade desta prática.

\section{Material e Métodos}

O experimento foi realizado por três anos consecutivos (1998, 1999 e 2000) nas várzeas do Estado do Tocantins, na entressafra do arroz irrigado, em solo classificado como Inceptissolo.

Nos dois primeiros anos, o estudo foi feito no Município de Formoso do Araguaia, na Cooperativa Mista Rural do Vale do Javaés - Coperjava (11²49' S e 49² $43^{\prime}$ W, a 130 m de altitude), usando a cultivar Rudá, no sistema de subirrigação. Utilizou-se o delineamento de blocos ao acaso, com quatro repetições, no esquema fatorial $5 \times 3$, ou seja, $0,40,80,120$ e $160 \mathrm{~kg} \mathrm{ha}^{-1}$ de $\mathrm{N}$ e os métodos e épocas de aplicação: na semeadura $\left(M_{1}\right), 1 / 2$ na semeadura $+1 / 2$ incorporado ao solo aos 20 dias após a emergência (DAE) $\left(\mathrm{M}_{2}\right)$ e $1 / 2$ na semeadura $+1 / 2$ a lanço aos 20 DAE $\left(\mathrm{M}_{3}\right)$. Por ocasião das semeaduras, aplicaram-se $120 \mathrm{~kg} \mathrm{ha}^{-1}$ de $\mathrm{P}_{2} \mathrm{O}_{5}$, na forma de superfosfato triplo, e $60 \mathrm{~kg} \mathrm{ha}^{-1}$ de $\mathrm{K}_{2} \mathrm{O}$, na forma de cloreto de potássio. No tratamento $\mathrm{M}_{2,}$ o fertilizante foi aplicado manualmente no sulco de $10 \mathrm{~cm}$ de profundidade, nas entrelinhas de plantio e, posteriormente, coberto com solo.

No terceiro ano, utilizou-se a cultivar Pérola, no delineamento de blocos ao acaso, com quatro repetições, avaliando-se todas as doses de $\mathrm{N}$ incorporadas ao solo aos 20 DAE, em três locais: no Município de Formoso do Araguaia na Companhia Brasileira de Agropecuária - Cobrape $\left(11^{\circ} 45^{\prime} \mathrm{S}\right.$ e $49^{\circ} 15^{\prime} \mathrm{W}$, a 115 m de altitude) e na Fazenda Verdes Campos (11 ${ }^{\circ} 49^{\prime} \mathrm{S}$ e $49^{\circ} 43^{\prime} \mathrm{W}$, a $130 \mathrm{~m}$ de altitude), e no Município de Lagoa da Confusão, na Fazenda Dona Carolina (1050' S e 49³3' W, a 90 m de altitude). As parcelas foram constituídas por seis linhas de $5 \mathrm{~m}$ de comprimento, com espaços de $0,40 \mathrm{~m}$, tendo, portanto, áreas total e útil de $12 \mathrm{~m}^{2} \mathrm{e} 3,2 \mathrm{~m}^{2}$, respectivamente. Após o preparo com grade, passou-se rolo compactador em toda área experimental, visando favorecer a subirrigação, mediante a redistribuição da água até a superfície do solo e, com isso, obter melhor estande de plântulas. A subirrigação é o método de irrigação no qual a água é aplicada diretamente sob a superfície do solo, geralmente por meio da criação, manutenção e controle do lençol freático a uma profundidade preestabelecida. Nos três locais, por ocasião das semeaduras, aplicaram-se $400 \mathrm{~kg} \mathrm{ha}^{-1}$ da fórmula 8-28-16. A adubação nitrogenada foi feita na forma de sulfato de amônio, no primeiro ano, e de uréia, nos dois últimos.

Os resultados das análises químicas, composição granulométrica e classe textural das amostras de solo coletadas no início da instalação de cada experimento, na 
camada de 0,00 a $0,15 \mathrm{~m}$ de profundidade encontram-se na Tabela 1. As análises das amostras de solo foram realizadas de acordo com método apresentado por Silva (1999).

Por ocasião da colheita, foram determinados número de plantas por área, vagens por planta, grãos por vagem, massa de 100 grãos e produtividade de grãos, a qual foi expressa em $\mathrm{kg} \mathrm{ha}^{-1}$, após ajustada em $13 \%$ de umidade.

Os dados obtidos foram submetidos à análise de variância e, quando significativos, à análise de regressão. $\mathrm{O}$ estudo da viabilidade econômica do feijoeiro foi realizado mediante as considerações da relação benefício/custo (B/C), com base nos preços do produto e dos fatores da produção, em vigor no mês de abril de cada ano. A dose máxima econômica foi calculada igualando-se a derivada primeira da função de produção, determinada por meio da equação de regressão com a relação de preços do $\mathrm{N}$ e do feijão. Considerando apenas o ano de 2000, em função de doses de N, foi possível determinar a dose e a produtividade econômicas. Para isso, o estudo teve como base os preços dos fatores, em Goiânia, GO, e o preço da saca de $60 \mathrm{~kg}$, recebido pelo produtor de feijão em Goiás, de $\mathrm{R} \$ 65,00$, em abril de 2001. Com isso, obteve-se a relação fator/produto $(\mathrm{RFP})=$ preço do fator $(\mathrm{PF}) /$ preço do produto $(\mathrm{PP})$. Assim, $\mathrm{RFP}=$ preço do $\mathrm{N}$ da uréia $(\mathrm{kg}) /$ preço do produto $(\mathrm{kg})$ e $\mathrm{RFP}=\mathrm{R} \$ 1,033 / \mathrm{R} \$ 1,083=0,954$

\section{Resultados e Discussão}

O comportamento do feijoeiro diferiu de ano para ano, o que pode ser atribuído à variabilidade do ambiente, especialmente dos solos de várzeas. Isto enfatiza a importância de se avaliar os efeitos do manejo de $\mathrm{N}$ sobre a resposta do feijoeiro em várias colheitas.

No primeiro ano, o feijoeiro respondeu linearmente às doses de sulfato de amônio. Embora este fertilizante contenha $\mathrm{S}$ do sulfato, a resposta do feijoeiro ao $\mathrm{N}$ é muito mais expressiva que ao $\mathrm{S}$, especialmente nos solos das várzeas em que o estudo foi conduzido, nos quais o S e a matéria orgânica se apresentavam em níveis adequados. Como apenas $5 \%$ a $10 \%$ do S aplicado é aproveitado pela cultura, enquanto cerca de $20 \%$ é adsorvido pelos colóides de Fe e Al, argila e matéria orgânica do solo (Oliveira et al., 1996), a discussão sobre a resposta do feijoeiro foi feita considerando-se apenas a aplicação de nitrogênio. As doses de $\mathrm{N}$ aumentaram linearmente o número de grãos por vagem, independentemente dos métodos e épocas de aplicação (Tabela 2). Houve interação entre doses de $\mathrm{N}$ e métodos e épocas de aplicação no número de vagens por planta e na produtividade (Tabela 3 ). Os efeitos do nutriente no número de vagens por planta contribuíram para o aumento da produtividade, pois este componente é o que normalmente mais se correlaciona com essa variável. As doses de $\mathrm{N}$ aumentaram linearmente o número de vagens por planta e a produtividade de feijão, e os efeitos mais expressivos ocorreram em $\mathrm{M}_{1}$ e $\mathrm{M}_{2}$, pois houve rendimento de $5,8 \mathrm{~kg} \mathrm{ha}^{-1}$, $6,3 \mathrm{~kg} \mathrm{ha}^{-1} \mathrm{e} 3,2 \mathrm{~kg} \mathrm{ha}^{-1}$ de grãos de feijão por $\mathrm{kg}$ de $\mathrm{N}$ aplicado nos métodos e épocas $\mathrm{M}_{1}, \mathrm{M}_{2}$ e $\mathrm{M}_{3}$, respectivamente. No método e época $\mathrm{M}_{1}$, a massa de 100 grãos também aumentou linearmente com as do-

Tabela 1. Atributos químicos, composição granulométrica e classe textural de amostras de solo das áreas experimentais.

\begin{tabular}{|c|c|c|c|c|c|}
\hline Características & $\begin{array}{c}\text { Coperjava } \\
(1998)\end{array}$ & $\begin{array}{c}\text { Coperjava } \\
\text { (1999) }\end{array}$ & $\begin{array}{l}\text { Cobrape } \\
(2000)\end{array}$ & $\begin{array}{c}\text { Verdes Campos } \\
(2000)\end{array}$ & $\begin{array}{c}\text { Dona Carolina } \\
(2000)\end{array}$ \\
\hline $\mathrm{pH}$ em $\mathrm{H}_{2} \mathrm{O}$ & 5,9 & 5,5 & 5,5 & 6,0 & 5,5 \\
\hline $\mathrm{MO}\left(\mathrm{g} \mathrm{kg}^{-1}\right)$ & 34 & 47 & 55 & 66 & 32 \\
\hline $\mathrm{Ca}\left(\mathrm{cmol} \mathrm{kg}^{-1}\right)$ & 2,3 & 2,1 & 3,9 & 3,5 & 1,8 \\
\hline $\mathrm{Mg}\left(\mathrm{cmolc}^{-1} \mathrm{~kg}^{-1}\right)$ & 1,4 & 1,6 & 1,5 & 0,9 & 0,5 \\
\hline $\mathrm{P}\left(\mathrm{mg} \mathrm{kg}^{-1}\right)$ & 41,2 & 25,8 & 66,0 & 13,7 & 5,5 \\
\hline $\mathrm{K}\left(\mathrm{mg} \mathrm{kg}^{-1}\right)$ & 154 & 78 & 162 & 51 & 197 \\
\hline $\mathrm{Al}\left(\mathrm{cmolc} \mathrm{kg}^{-1}\right)$ & 0,1 & 0,5 & 0,5 & 0,0 & 0,3 \\
\hline $\mathrm{Cu}\left(\mathrm{mg} \mathrm{kg}^{-\rho}\right)$ & 2,6 & 2,3 & 2,3 & 2,3 & 1,6 \\
\hline $\mathrm{Zn}\left(\mathrm{mg} \mathrm{kg}^{-1}\right)$ & 5,0 & 2,4 & 3,7 & 4,0 & 2,0 \\
\hline $\mathrm{Fe}\left(\mathrm{mg} \mathrm{kg}^{-1}\right)$ & 110 & 95 & 198 & 121 & 341 \\
\hline $\operatorname{Mn}\left(\mathrm{mg} \mathrm{kg}^{-1}\right)$ & 7 & 12 & 30 & 13 & 28 \\
\hline $\mathrm{H}+\mathrm{Al}\left(\mathrm{cmolc} \mathrm{kg}^{-1}\right)$ & 3,5 & 11,75 & 11,2 & 7,5 & 8,6 \\
\hline Argila $\left(\mathrm{g} \mathrm{kg}^{-1}\right)$ & 355 & 265 & 300 & 320 & - \\
\hline Silte $\left(\mathrm{g} \mathrm{kg}^{-1}\right)$ & 210 & 290 & 115 & 170 & - \\
\hline Areia $\left(\mathrm{g} \mathrm{kg}^{-1}\right)$ & 435 & 445 & 585 & 410 & - \\
\hline Classe textural & Franco-argiloso & Franco-argiloso & Franco-argilo-arenoso & Franco-argiloso & - \\
\hline
\end{tabular}


ses de nitrogênio. Resultados semelhantes foram obtidos por Villalobos (1980) e Silva \& Silveira (2000). A deficiência de $\mathrm{N}$ reduz o número de flores do feijoeiro e, conseqüentemente, o número de vagens, e as sementes tornam-se pequenas, o que acarreta baixa massa de grãos (Oliveira et al., 1996).

No segundo ano, houve efeito do $\mathrm{N}$ e da interação $\mathrm{N}$ com métodos e épocas de aplicação na produtividade e diversas características agronômicas. Houve interação entre doses de $\mathrm{N}$ e métodos e épocas de aplicação no número de vagens por planta e na produtividade. Houve efeito linear de doses de N sobre o número de vagens por planta, nos métodos e épocas $\mathrm{M}_{1}$ e $\mathrm{M}_{2}$ (Tabela 3). Os efeitos das doses de $\mathrm{N}$ foram lineares em relação aos três métodos e épocas de aplicação na produtividade do feijoeiro, havendo aumento de $10,6 \mathrm{~kg} \mathrm{ha}^{-1}, 9,9 \mathrm{~kg} \mathrm{ha}^{-1}$ e 5,3 $\mathrm{kg} \mathrm{ha}^{-1} \mathrm{de}$ grãos de feijão para cada $\mathrm{kg}$ de $\mathrm{N}$ aplicado nos métodos e épocas $\mathrm{M}_{1}, \mathrm{M}_{2}$ e $\mathrm{M}_{3}$, respectivamente. Com isso, a aplicação a lanço de parte do $\mathrm{N}$ propiciou menor resposta do feijoeiro, indicando provavelmente a ocorrência de maiores perdas de $\mathrm{NH}_{3}$ quando o fertilizante nitrogenado foi aplicado na superfície do solo. Em virtude do rápido crescimento das plantas em várzeas tropicais, a incorporação de $\mathrm{N}$ deve ser feita antes do fechamento das entrelinhas.

No último ano, na Cobrape, o feijoeiro expressou maior potencial produtivo em comparação aos demais estudos. Isto se deve provavelmente aos nutri-

Tabela 2. Equações de regressão da produtividade e de algumas características agronômicas do feijoeiro obtidas em razão da aplicação de doses de $\mathrm{N}$ e coeficientes de determinação $\left(\mathrm{R}^{2}\right)$, em 1998, independentemente dos métodos e épocas de aplicação e 2000 , incorporadas ao solo aos 20 dias após a emergência.

\begin{tabular}{|c|c|c|}
\hline Característica & Equação de regressão & $\mathrm{R}^{2}$ \\
\hline Grãos por vagem & $\begin{array}{c}\text { Coperjava (1998) } \\
\mathrm{Y}=4.23+0,0035 \mathrm{X}\end{array}$ & $0,436^{*}$ \\
\hline $\begin{array}{l}\text { Massa de } 100 \text { grãos (g) } \\
\left.\text { Produtividade (kg ha }{ }^{-T}\right)\end{array}$ & $\begin{array}{l}\text { Dona Carolina (2000) } \\
\mathrm{Y}=22,52+0,08994 \mathrm{X}-0,00041 \mathrm{X}^{2} \\
\mathrm{Y}=515.92+10.45267 \mathrm{X}\end{array}$ & $\begin{array}{l}0,998 \text { ** } \\
0.986\end{array}$ \\
\hline $\begin{array}{l}\text { Vagens por planta } \\
\text { Grãos por vagem } \\
\text { Massa de } 100 \text { grãos }(\mathrm{g}) \\
\text { Produtividade }\left(\mathrm{kg} \mathrm{ha}^{-1}\right) \\
\end{array}$ & $\begin{array}{l}\quad \text { Verdes Campos (2000) } \\
\mathrm{Y}=3,65+0,05450 \mathrm{X} \\
\mathrm{Y}=3,43+0,02594 \mathrm{X}-0,00012 \mathrm{X}^{2} \\
\mathrm{Y}=14,42+0,04440 \mathrm{X} \\
\mathrm{Y}=224.12+10.54300 \mathrm{X}\end{array}$ & $\begin{array}{l}0,928 \text { ** } \\
0,995^{* *} \\
0,918 * \\
0,982^{* *}\end{array}$ \\
\hline $\begin{array}{l}\text { Vagens por planta } \\
\text { Massa de } 100 \text { grãos (g) } \\
\text { Produtividade }\left(\mathrm{kg} \mathrm{ha}^{-1}\right)\end{array}$ & $\begin{array}{l}\text { Cobrape }(2000) \\
Y=2,95+0,11864 X-0,00037 X^{2} \\
Y=20,63+0,02605 X \\
Y=883.86+21.33314 X-0.06086 X^{2}\end{array}$ & $\begin{array}{l}0,952^{*} \\
0,908 \\
0,999\end{array}$ \\
\hline
\end{tabular}

Pesq. agropec. bras., Brasília, v. 38, n. 11, p. 1265-1271, nov. 2003 entes essenciais do solo daquele local se encontrarem em níveis mais adequados (Tabela 1) e a sua classe textural possibilitar uma melhor combinação entre água e ar na zona das raízes, resultando em condições mais favoráveis para o desenvolvimento do feijoeiro em várzeas. Como o desenvolvimento do sistema radicular do feijoeiro no cultivo em várzeas é muito superficial, aproximadamente $0,05 \mathrm{~m}$, o teor de umidade do solo nesta camada deve se encontrar em níveis adequados para o seu desenvolvimento (Santos, 2002). Isto evidencia que na semeadura de feijoeiro em várzeas tropicais não há necessidade de se empregar práticas que possibilitem a drenagem da camada superficial do solo, pois na entressafra do arroz raramente ocorre precipitação pluvial. Com isso, o controle da umidade em camadas mais profundas do solo de várzeas tropicais pode ser prejudicial para o feijoeiro nesse sistema de cultivo. Frizzone et al. (1987) e Stone \& Moreira (2001) constataram que a resposta do feijoeiro às doses de $\mathrm{N}$ difere em razão da disponibilidade hídrica no solo. Na Cobrape, o efeito das doses de $\mathrm{N}$ sobre a produtividade ajustou-se ao modelo quadrático; $175 \mathrm{~kg} \mathrm{ha}^{-1}$ de $\mathrm{N}$ incorporados ao solo aos 20 DAE foi a dose estimada pela equação de regressão para a obtenção de $2.753 \mathrm{~kg} \mathrm{ha}^{-1}$ de grãos da cultivar Pérola. Esta dose estimada ultrapassa apenas em $9 \%$ o limite da dose

Tabela 3. Equações de regressão da produtividade e de algumas características agronômicas do feijoeiro obtidas em razão da interação entre doses e métodos e épocas de aplicação de $\mathrm{N}$ e coeficientes de determinação $\left(\mathrm{R}^{2}\right)$, em 1998 e 1999.

\begin{tabular}{|c|c|c|c|}
\hline Característica & $\begin{array}{c}\text { Método e } \\
\text { época (1) }\end{array}$ & Equação de regressão & $\mathrm{R}^{2}$ \\
\hline $\begin{array}{l}\text { Vagens por planta } \\
\text { Vagens por planta } \\
\text { Vagens por planta } \\
\text { Massa de } 100 \text { grãos }(\mathrm{g}) \\
\text { Produtividade de grãos }\left(\mathrm{kgha}^{-1}\right) \\
\text { Produtividade de grãos }\left(\mathrm{kgha}^{-1}\right) \\
\text { Produtividade de grãos }\left(\mathrm{kgha}^{-1}\right)\end{array}$ & $\begin{array}{l}\mathrm{M}_{1} \\
\mathrm{M}_{2} \\
\mathrm{M}_{3} \\
\mathrm{M}_{1} \\
\mathrm{M} 1 \\
\mathrm{M}_{2} \\
\mathrm{M}_{3}\end{array}$ & $\begin{aligned} 1998 \\
Y=3,14+0,0823 X \\
Y=4,46+0,0366 X \\
Y=3,63+0,0281 X \\
Y=9,99+0,0756 X \\
Y=207,90+5,7513 X \\
Y=270,25+6,2600 X \\
Y=242.95+32144 X\end{aligned}$ & $\begin{array}{l}0,913^{* * *} \\
0.719^{* *} \\
0,877^{* *} \\
0,587^{* * *} \\
0,986^{* *} \\
0.848^{* * *} \\
0.912^{*}\end{array}$ \\
\hline $\begin{array}{l}\text { Vagens por planta } \\
\text { Vagens por planta } \\
\text { Produtividade de grãos }\left(\mathrm{kgha}^{-1}\right) \text { ) } \\
\text { Produtividade de grãos }\left(\mathrm{kgha}^{-1}\right) \\
\text { Produtividade de grãos }\left(\mathrm{kgha}^{-1}\right)\end{array}$ & $\begin{array}{l}\mathrm{M}_{1} \\
\mathrm{M}_{2} \\
\mathrm{M}_{1} \\
\mathrm{M}_{2} \\
\mathrm{M} 3 \\
\end{array}$ & $\begin{array}{l}1999 \\
Y=4,82+0,0798 X \\
Y=6,55+0,0364 X \\
Y=1039,60+10,5644 X \\
Y=1118,60+9,8581 X \\
Y=1429,85+5,2950 X\end{array}$ & $\begin{array}{r}0,913^{* *} \\
0,607^{* * *} \\
\times 0,928^{* *} \\
0,941^{* *} \\
0,859^{* *} \\
\end{array}$ \\
\hline
\end{tabular}


máxima estudada, portanto, a mesma pode ser considerada como sendo a dose máxima. A aplicação de $32 \mathrm{~kg} \mathrm{ha}^{-1}$ de $\mathrm{N}$ mediante o formulado na semeadura e da maior quantidade de $\mathrm{N}$ incorporada ao solo aos 20 DAE resultou em maior resposta do feijoeiro. Avaliando os efeitos do parcelamento de $75 \mathrm{~kg} \mathrm{ha}^{-1}$ de $\mathrm{N}$ na cultura do feijoeiro irrigado em terras altas, Soratto (2002) verificou que a aplicação de todo o N em cobertura aos 22 DAE proporcionou maior produtividade de grãos, $2.651 \mathrm{~kg} \mathrm{ha}^{-1}$, em comparação com todo o $\mathrm{N}$ na semeadura ou parte na semeadura e o restante em cobertura.

A dose necessária para a máxima eficiência técnica, ou seja, aquela que proporcionou $90 \%$ do valor máximo da produtividade de grãos, foi de $108 \mathrm{~kg} \mathrm{ha}^{-1} \mathrm{de}$ Nincorporados ao solo aos 20 DAE (Figura 1), portanto, bastante similar às obtidas por Kikuti et al. (2002).Este efeito do N pode ser atribuído à sua maior disponibilidade na época do florescimento, resultando em benefícios diretos para os componentes da produtividade. Assim, o número máximo de vagens por planta foi de 12,5, estimado com a dose de máxima eficiência técnica (160 kg ha-1 de N). A massa de 100 grãos aumentou linearmente com o aumento das doses de $\mathrm{N}$ (Tabela 2). De modo geral, esta característica é pouco influenciada pelo nitrogênio. Efeitos de $\mathrm{N}$ sobre a massa de 100 grãos somente têm sido observados em avaliações nas maiores doses desse nutriente, como no estudo de Silveira \& Damasceno (1993), quando foram aplicados $90 \mathrm{~kg} \mathrm{ha}^{-1} \mathrm{de} \mathrm{N}$, em condições irrigadas.

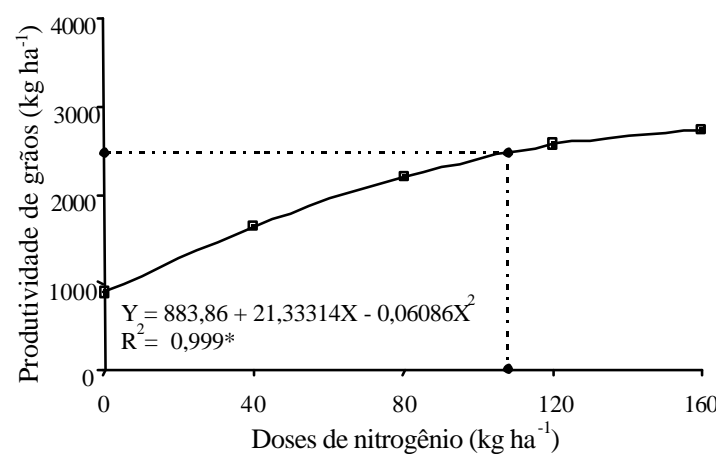

Figura 1. Produtividade de grãos da cultivar Pérola de feijoeiro em resposta às doses de nitrogênio incorporadas ao solo aos 20 dias após a emergência, na Cobrape. As linhas pontilhadas indicam que $90 \%$ da produtividade fisiológica (2.478 $\left.\mathrm{kg} \mathrm{ha}^{-1}\right)$ foi obtida com $108 \mathrm{~kg} \mathrm{ha}^{-1}$ de nitrogênio.
Na Fazenda Verdes Campos, o número de vagens por planta e a massa de 100 grãos aumentaram linearmente e o número de grãos por vagem teve resposta quadrática, sendo o valor máximo de 4,8 grãos por vagem estimado com $108 \mathrm{~kg} \mathrm{ha}^{-1}$ de $\mathrm{N}$ incorporados ao solo aos 20 DAE (Tabela 2). Na Fazenda Dona Carolina, o único componente da produtividade afetado pelo $\mathrm{N}$ foi a massa de 100 grãos, cujo efeito foi quadrático, e o valor máximo estimado foi de $27,5 \mathrm{~g}$ com $110 \mathrm{~kg} \mathrm{ha}^{-1}$ de $\mathrm{N}$ incorporados ao solo aos 20 DAE. Na Verdes Campos e na Dona Carolina, os modelos que melhor descreveram os efeitos das doses foram os lineares, ou seja, as doses de $\mathrm{N}$ utilizadas não foram suficientes para atingirem as produtividades máximas, mostrando que o feijoeiro demandou mais nitrogênio. Nestes dois locais, os rendimentos por $\mathrm{kg}$ de $\mathrm{N}$ aplicado foram similares, $10,54 \mathrm{~kg}$ e $10,45 \mathrm{~kg}$, respectivamente.

A eficiência de utilização das fontes de $\mathrm{N}$ mais empregadas no Brasil é baixa, ao redor de $50 \%$ (Fageria et al., 1999). O que explica, em parte, a resposta do feijoeiro a altas doses desse nutriente. Nos três anos, a necessidade de $\mathrm{N}$ para o feijoeiro em várzeas foi superior à verificada no sistema de cultivo irrigado de terras altas, cujas respostas máximas ocorreram com $72 \mathrm{~kg} \mathrm{ha}^{-1}$ (Silveira \& Damaceno, 1993), $109 \mathrm{~kg} \mathrm{ha}^{-1}$ (Silva \& Silveira, 2000), $137 \mathrm{~kg} \mathrm{ha}^{-1}$ (Barbosa Filho \& Silva, 1994; Stone \& Moreira, 2001) e $150 \mathrm{~kg} \mathrm{ha}^{-1}$ (Cardoso et al., 1978). Ademais, Kikuti et al. (2002) estimaram as respostas máximas do feijoeiro em $2.332 \mathrm{~kg} \mathrm{ha}^{-1}, 1.532 \mathrm{~kg} \mathrm{ha}^{-1}$ e $2.161 \mathrm{~kg} \mathrm{ha}^{-1}$ com as doses de 170,124 e $191 \mathrm{~kg} \mathrm{ha}^{-1}$ de $\mathrm{N}$, nos cultivos de inverno de 2000 sob irrigação, na estação chuvosa de 2000/2001 e 2001/2002, respectivamente.

A elevada exigência de $\mathrm{N}$ pelo feijoeiro em várzea possivelmente se deve aos resíduos deixados na superfície do solo pela cultura do arroz irrigado que propiciaram maior imobilização e menor disponibilidade do nutriente para a cultura; parte do $\mathrm{N}$ foi provavelmente consumida pela população microbiana do solo no processo de decomposição da palhada do arroz. Apesar de não se ter determinado a quantidade de palhada de arroz deixada sobre o solo, podese admitir que foi elevada, pois nessas áreas de várzea são obtidas altas produtividades deste cereal. A magnitude em que a imobilização do $\mathrm{N}$ mineral afeta a sua disponibilidade para a cultura subseqüente 
depende da relação $\mathrm{C} / \mathrm{N}$, composição e quantidade de resíduos produzidos pela cultura anterior (Fageria et al., 1999).

Em 1999, a melhor relação benefício/custo (B/C) foi de 1,31, ou seja, o produtor obteve $31 \%$ de lucratividade com a dose de $160 \mathrm{~kg} \mathrm{ha}^{-1}$ de N, aplicando-se $1 / 2$ na semeadura e $1 / 2$ incorporado ao solo aos 20 DAE, tendo a uréia como fonte. Em 2000, com $160 \mathrm{~kg} \mathrm{ha}^{-1}$ de $\mathrm{N}$ incorporados ao solo aos $20 \mathrm{DAE}$, usando-se como fonte de $\mathrm{N}$ a uréia, na Fazenda Verdes Campos obteve-se a relação de B/C de 1,67 e na Dona Carolina de 1,69. Já na Cobrape, nesse mesmo ano, com a mesma dose de $\mathrm{N}$ e o mesmo método e época de aplicação, obteve-se a maior relação de B/C $(2,43)$. Considerando-se a função da produção obtida na Cobrape, foi possível determinar a dose econômica de $\mathrm{N}$ de $167 \mathrm{~kg} \mathrm{ha}^{-1}$ de $\mathrm{N}$ incorporados ao solo aos 20 DAE para uma produtividade de $2.700 \mathrm{~kg} \mathrm{ha}^{-1}$ de grãos, ou seja, bem próximas da dose ótima e da produtividade máxima fisiológica, o que resulta em maior eficiência de utilização de nitrogênio. A resposta do feijoeiro ao nutriente corresponde à aplicação total de $\mathrm{N}$ que foi a incorporação ao solo aos 20 DAE desta dose, além de $32 \mathrm{~kg} \mathrm{ha}^{-1}$ de $\mathrm{N}$ por ocasião da semeadura, mostrando que está bem acima dos valores ótimos econômicos de 69 a $100 \mathrm{~kg} \mathrm{ha}^{-1}$ (Silva \& Silveira, 2000), $114 \mathrm{~kg} \mathrm{ha}^{-1}$ (Frizzone et al., 1987), $129 \mathrm{~kg} \mathrm{ha}^{-1}$ (Stone \& Moreira, 2001) e $132 \mathrm{~kg} \mathrm{ha}^{-1}$ (Barbosa Filho \& Silva, 1994).

\section{Conclusões}

1. O feijoeiro demanda mais nitrogênio em várzeas que nos sistemas tradicionais de cultivo em terras altas.

2. A aplicação de parte do nitrogênio incorporada ao solo é mais eficaz que a aplicação a lanço na superfície.

3. A adubação nitrogenada na cultura do feijoeiro em várzeas tropicais propicia ao produtor ganho econômico considerável em razão da resposta da planta ao nutriente.

\section{Referências}

ALMEIDA, L. D. de; BULISANI, E.; GALLO, P. B.; SABINO, J. C. Respostas de três cultivares de feijoeiro à adubação nitrogenada. In: REUNIÃO NACIONAL DE PESQUISA DE FEIJÃO, 1., 1982, Goiânia. Anais... Goiânia: Embrapa-CNPAF, 1982. p. 184-187.

BARBOSA FILHO, M. P.; SILVA, O. F. da. Aspectos agroeconômicos da calagem e da adubação nas culturas de arroz e de feijão irrigados por aspersão. Pesquisa Agropecuária Brasileira, Brasília, v. 29, n. 11, p. 1657 1667, nov. 1994.

CARDOSO, A. A.; FONTES, L. A. N.; VIEIRA, C. Efeito de fontes e doses de adubo nitrogenado sobre o feijão (Phaseolus vulgaris L.). Revista Ceres, Viçosa, MG, v. 25, p. 292-295, 1978.

FAGERIA, N. K.; STONE, L. F.; SANTOS, A. B. dos. Maximização da eficiência de produção das culturas. Brasília: Embrapa-SCT/Embrapa-CNPAF, 1999. 294 p.

FEITOSA, C. T.; RONZELLI JUNIOR, P.; ALMEIDA, L. D. de; VEIGA, A. A.; HIROCE, R.; JORGE, J. P. N. Adubação NP para o feijoeiro na presença e ausência de calcário. Revista Brasileira de Ciência do Solo, Campinas, v. 4, n. 3, p. 156-159, 1980.

FRIZZONE, J. A.; OLITTA, A. F. L.; PEREIRA, G. T. Funções de resposta do feijoeiro (Phaseolus vulgaris L.) ao uso de nitrogênio e lâmina de irrigação - II: maximização da receita líquida. ITEM, Brasília, n. 30, p. 27-31, 1987.

KIKUTI, H.; ANDRADE, M. J. B. de; VIEIRA, N. M. B.; SILVA, V. M. P. e. Produtividade do feijoeiro-comum em função de doses de nitrogênio e fósforo. In: CONGRESSO NACIONAL DE PESQUISA DE FEIJÃO, 7., 2002, Viçosa, MG. Resumos expandidos... Viçosa: UFV, 2002. p. 709-711.

OLIVEIRA, I. P. de; ARAUJO, R. S.; DUTRA, L. G. Nutrição mineral e fixação biológica de nitrogênio. In: ARAUJO, R. S.; RAVA, C. A.; STONE, L. F.; ZIMMERMANN, M. J. de O. (Coord.). Cultura do feijoeiro comum no Brasil. Piracicaba: Potafos, 1996. p. $169-221$.

SANTOS, A. B. dos. Desenvolvimento de técnicas para a produção de grãos em várzeas. Santo Antônio de Goiás: Embrapa-CNPAF, 2002. 17 p.

SANTOS, A. B. dos; SILVEIRA, P. M. da. Cultivo em várzeas. In: ARAUJO, R. S.; RAVA, C. A.; STONE, L. F.; 
ZIMMERMANN, M. J. de O. (Coord.). Cultura do feijoeiro comum no Brasil. Piracicaba: Potafos, 1996. p. 589-617.

SILVA, C. C. da; SILVEIRA, P. M. da. Influência de sistemas agrícolas na resposta do feijoeiro (Phaseolus vulgaris L.) irrigado à adubação nitrogenada em cobertura.PesquisaAgropecuária Tropical, Goiânia, v. 30, n. 1, p. 86-96, 2000.

SILVA, F. C. da (Org.). Manual de análises químicas de solos, plantas e fertilizantes. Brasília: Embrapa-SCT, 1999. $370 \mathrm{p}$.

SILVEIRA, P. M. da; DAMASCENO, M. A. Doses e parcelamento de $\mathrm{K}$ e de $\mathrm{N}$ na cultura do feijoeiro irrigado. Pesquisa Agropecuária Brasileira, Brasília, v. 28, n. 11, p. 1269-1276, nov. 1993.
SORATTO, R. P. Resposta do feijoeiro ao preparo do solo, manejo de água e parcelamento da adubação nitrogenada. 2002. 72 f. Dissertação (Mestrado em Agronomia) - Universidade Estadual Paulista, Ilha Solteira, 2002.

STONE, L. F.; MOREIRA, J. A. A. Resposta do feijoeiro ao nitrogênio em cobertura, sob diferentes lâminas de irrigação e preparos do solo. Pesquisa Agropecuária Brasileira, Brasília, v. 36, n. 3, p. 473-481, mar. 2001.

VILLALOBOS, R. A. Estudos sobre adubação nitrogenada da cultura do feijão (Phaseolus vulgaris L.) na Zona da Mata de Minas Gerais. 1980. 68 f. Dissertação (Mestrado em Fitotecnia) - Universidade Federal de Viçosa, Viçosa, MG, 1980. 